Article

\title{
Characterisation of the dynamics of leachate contamination plumes in the surrounding of the Hulene - B waste dump, Maputo, Mozambique
}

\author{
Bernardino Bernardo ${ }^{1,2}$, Carla Candeias ${ }^{1}$, Fernando Rocha ${ }^{1, *}$ \\ 1 GeoBioTec Research Centre, Department of Geosciences, University of Aveiro, \\ 3810-193, Aveiro, Portugal. candeias@ua.pt; tavares.rocha@ua.pt. \\ 2 Faculty of Earth Sciences and Environment, Pedagogic University of Maputo, Mozam- \\ bique. nhacundela.berna@gmail.com; bernardino.bernardo@ua.pt. \\ * Correspondence: Fernando Rocha, tavares.rocha@ua.pt
}

\begin{abstract}
The contamination of areas around solid urban waste dumps is a global challenge for the maintenance of environmental quality in large urban centres in developing countries. This study applied geophysical methods (electrical resistivity) to identify leachate contamination plumes in the subsoil and groundwater, as well as to describe their temporal (2020 and 2021) dynamics in the lithology and groundwater around the Hulene - B waste dump, Maputo, Mozambique. Geophysical methods (electrical resistivity) were applied to identify possible groundwater contamination plumes, their dynamics, mechanisms of their enrichment and dispersion. Eight $400 \mathrm{~m}$ electrical resistivity profiles were performed, four profiles in January 2020 and four profiles in May 2021, overlapped, and the data were inverted with RES2D software. The electrical resistivity models indicate an $\mathrm{E}-\mathrm{W}$ movement of large contamination plumes that dilute superficially into the natural surface water receiving basin and groundwater, creating zones of resistive anomalies. The thickness of the plumes in the subsurface environment was shown to be extensive in summer for profiles $1 \mathrm{a}$ and $2 \mathrm{~b}$ and we associate it with the higher leachate production and migration mechanisms, which are intense in the hot and rainy season. Profile $4 \mathrm{~b}$ showed the propagation of anomalous surface and subsurface areas, which was associated with higher leachate production and migration process in the new deposition zone (west). The spatial distribution of contamination plumes at both stations reduced significantly as we moved further away from the waste deposit, revealing the attenuating effect of groundwater and lithological substrate (Profile $3 a, b$, and fig.7).
\end{abstract}

Keywords: Plumes, dynamics, resistivity, contamination, groundwater.

\section{Introduction}

In recent decades, waste generation has been increasing in quantity and diversity worldwide, resulting from population explosion and economic growth [1,2]. The global annual production of municipal solid waste (MSW) in 2025 is expected to reach about 2.2 billion metric tons [3]. This fact implies many challenges in defining and managing the final disposal sites for municipal solid waste $[4,5]$. It is estimated that about $33 \%$ of municipal solid waste produced worldwide is disposed of improperly [3]. Thus, several studies have reported environmental problems associated with poor solid waste disposal [6]. Morita et al. [7] estimate that open dumpsites will account for $10 \%$ of global greenhouse gas emissions by 2025. Municipal solid waste when disposed of produces leachate, which is a highly contaminated liquid containing high amounts of inorganic 
ions, organic compounds, and other toxic elements such as heavy metals and ammonia $[8,9]$. In unplanned landfills, leachate is likely to be mobilised to the surrounding environment (soils, surface, and groundwater) causing contamination [10]. Kumar et al. [11] and Khattak et al. [12] have shown that waste dump in areas with high temperatures and precipitation, the process of waste decomposition and leachate production is higher. The greatest environmental impacts resulting from environmental contamination by waste are described in developing countries, where the planning of waste disposal sites is very deficient [13]. In Mozambique and in Maputo city in particular, the production of municipal solid waste has been increasing and daily waste production is estimated to be around 1250 tonnes [14, 15, 16]. Of these, about 1000 tons are deposited in the largest open-air dump in Maputo city, the Hulene - B dump [17]. In this dump all types of waste, food, electronic, construction, health and industrial are deposited without any treatment [14, 17]. Studies developed by Nogueira et al. [18] and Vicente et al. [19] denounced a possible contamination of soils and groundwater in the environment around the Hulene - B dump, which suggests the need for its continuous study and monitoring of its geo-environmental context [20].

Many methods are currently used to study contamination problems in solid waste disposal areas and geophysical methods are pointed out as effective in identifying waste contaminated areas [21, 22]. Among these methods, electrical resistivity is widely applied due to its non-invasive nature in data acquisition and processing [23, 24, 25]. Arifin et al. [26] and Lau et al. [27] demonstrated electrical resistivity to be effective in locating buried hazardous waste, identification of contamination plumes resulting from leachate flow.

In general, the typical resistivity of a waste mass that can range between 15 and 30 $\Omega . \mathrm{m}$ in a saturated medium, or between $30-70 \Omega . \mathrm{m}$ in an unsaturated medium [28]. However, certain materials present in a waste mass can increase or further decrease the resistivity values [28, 29]. Ashes from incinerating plants, tree cuttings and textiles (when they can retain moisture), previously treated waste and chemicals give rise to low resistivities, however plastics, rubber, certain types of building demolition rubble, rubbish preserved inside plastic bags, heavily compacted newspapers and organic chemicals have very high resistivities $[25,29]$. The reference resistivity for sandy soils is $50-100 \Omega . m$ $[30,31]$. This study applied the geophysical method (electrical resistivity) to identify the leachate contamination plumes and describe their temporal dynamics in surrounding of the Hulene - B Waste dump, Maputo, Mozambique (2020 and 2021).

\section{Materials and Methods}

\subsection{Study area}

The Hulene - B dump is in the Hulene-B neighbourhood, northern direction of Maputo city, Mozambique (Fig.1) [17, 20], a residential area with approximately 27,996 inhabitants. The dump receives all types of waste produced in Maputo City [15, 19, 32, 33]. The height of the waste is estimated to be about $6 \mathrm{~m}$ to $15 \mathrm{~m}$ and occupies an area of 17 hectares [34]. The dump is in a former quarry with no previous preparation for waste reception [35]. These characteristics are described as conducive to contamination of the local hydrogeological system [36]. Sallwey et al. [37], Serra [32] and Vicente et al. [19] have associated the Hulene-B dump with contamination of groundwater and soils by heavy metals in its surroundings $(\mathrm{Hg}, \mathrm{As}, \mathrm{Pb}, \mathrm{Cu}$ and $\mathrm{Zn})$. The Hulene - $\mathrm{B}$ hydrogeological system is part of the Tertiary - Quaternary aquifer system [18]. The aquifer substrate is formed by the layer of clayey marl to grey clay $[18,38]$. In the surroundings of the Hulene - B dump the localised presence of the semi-impermeable layer (clayey sands), between the fine to coarse sand and the sandstones, causes the water circulation of these two sectors to continuously connect [39]. There are places where the coarse sands lie directly on top of the clay layer, developing semi-confined conditions[18, 39]. Nogueira et al. [38] showed that the aquifer system in Maputo city is prone to contamination. Geo- 
logically, the Hulene - B dump is inserted in the Mesocenozoic sedimentary basin of southern Mozambique [40], and is situated in a contact zone of two lithologies, Ponta Vermelha Formation and Malhazine (fig.1.b), on a gentle dune slope with east - west orientation [41]. The Ponta Vermelha Formation (TPv) dates from the upper Pliocene to the lower Plistocene and is composed in the upper part of ferruginous sandstones and red silty sands, which gradually change to yellow and whitish sands $[18,41]$. At the surface this unit presents a red colour, and poorly consolidated sands may appear [18]. The Malhazine Formation (QMa) dated to the upper Pleistocene and consists of course to fine, poorly consolidated sands with whitish to reddish colours, fixed by vegetation because of successive consolidation processes $[18,41]$. The soils in the surrounding of the Hulene - B dump have been classified as sandy dune [41]. The predominant climate is of subtropical type, with two seasons: (a) hot and rainy period from December to March with more than $60 \%$ of the annual precipitation, with the highest concentration of precipitation in January average $125 \mathrm{~mm}$ and (b) dry and cold season from April to September with lower temperatures in June and July, as well as a weak and irregular precipitation, whose minimum values are recorded in August $12 \mathrm{~mm}$. The average annual precipitation is $789,2 \mathrm{~mm}[42,43]$. The prevailing winds are SE [44].
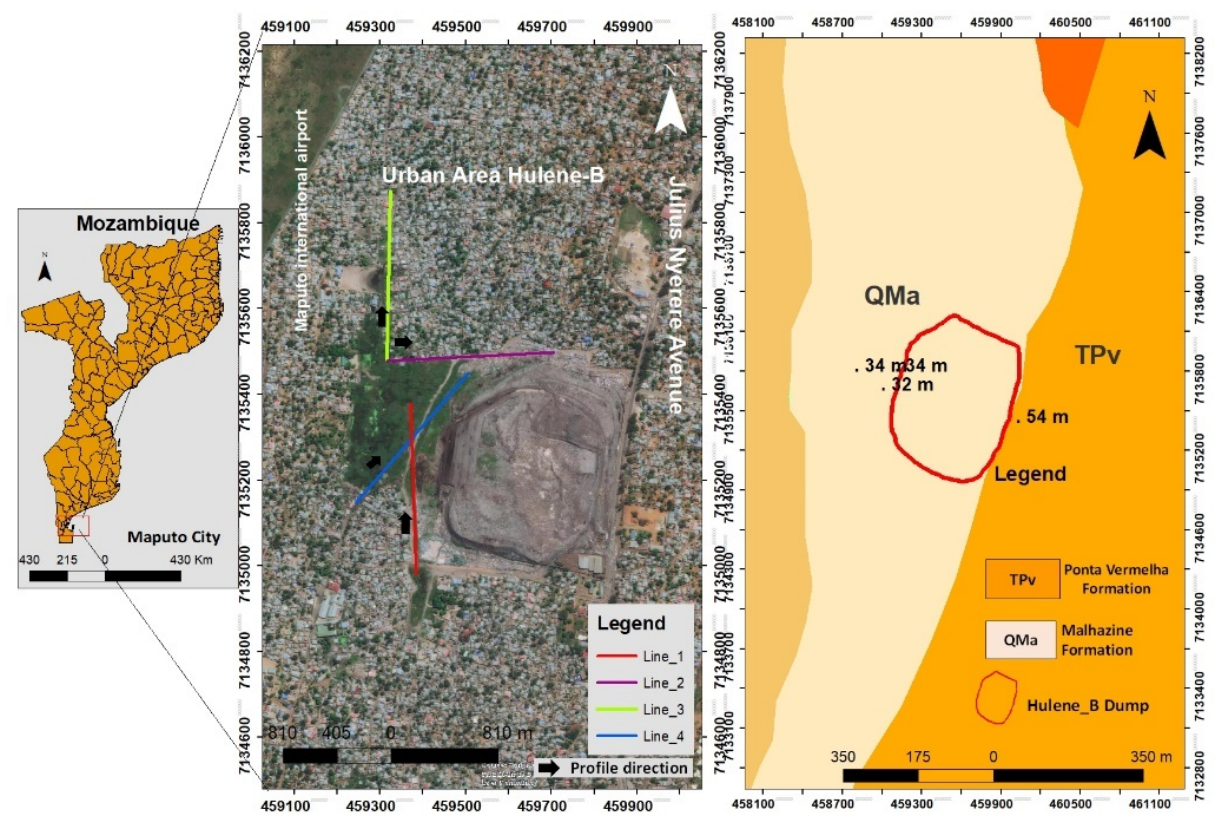

Figure 1. (a)Location, Geophysical survey lines and environment context(b) Geology and Topography. Adapt. Momade et al. [41].

\subsection{Geophysical Studies (Electrical Resistivity)}

In recent years with the awareness of the increasingly complex environmental issues, geophysical prospection methods started to be successfully used in the study of complex environments, such as urban areas [45,46]. Among the geophysical methods most employed in environmental studies the electrical resistivity has been pointed out as relevant [21, 22], and it has been prominent in the study of environmental problems in soil and groundwater, mainly in the location of buried hazardous waste, contamination from different sources and the planning of safe sites for the deposit of industrial and domestic waste $[26,28]$ being widely used to identify areas of heavy metal contamination, contamination plumes [10], groundwater [22, 47], lithological variations [26]. Leachates when they meet geological materials, cause the natural electrical resistivity of the material to decrease due to the high concentration of dissolved metal ions, creating anomalous resistive zones [27, 48]. 
The resistivity method is based on the electric current injected into the ground through a pair of electrodes (A and B - current electrodes) and the resulting potential difference between another pair of electrodes ( $\mathrm{M}$ and $\mathrm{N}$ - potential electrodes) [21, 27]. The ground resistivity is calculated from the distances between the electrodes, applied current and measured potential difference, based on the Law of Ohm [49]. The apparent resistivity of the soil can be determined, based on the known difference between the electric field potential $(\Delta \mathrm{V})$ and the current $(\mathrm{I})$, and the distance between the electrodes [27].

The resistivity is given by the equation:

$\mathrm{Qa}=k \frac{\Delta v}{I}$

Where: $\rho a$-resistivity of a bedrock, I-intensity of current applied to the soil by electrodes $\mathrm{AB}(\mathrm{mA}), \Delta \mathrm{V}$-differential potential between electrodes $\mathrm{MN}(\mathrm{mV})$, $\mathrm{k}$-geometrical coefficient of electrode positioning $(\mathrm{m})$.

The geometrical factor $\mathrm{k}$ is dependent on the distribution geometry of the electrodes, as follows:

$$
\mathrm{k}=\frac{2 \pi}{\left(\frac{\mathrm{l}}{\mathrm{NM}}-\frac{\mathrm{l}}{\mathrm{dM}}-\frac{\mathrm{l}}{\mathrm{NN}}+\frac{\mathrm{i}}{\mathrm{dN}}\right)}
$$

Where $\mathrm{AM}, \mathrm{BM}, \mathrm{AN}$ and $\mathrm{BN}$ represent the geometrical distance between the electrodes $\mathrm{A}$ and $\mathrm{M}, \mathrm{B}$ and $\mathrm{M}, \mathrm{A}$ and $\mathrm{N}$, and B and $\mathrm{N}$, respectively $[49,1]$.

The electrical resistivity of the terrains is a characteristic closely linked to the type, nature, and state of alteration of the geological formations [24,50]. Thus, the method allows: (1) the identification of the lithology of landfill subsoil; (2) the determination of the groundwater table depth; (3) the determination of the distribution of the contamination zones and the direction of the pollutant migration; and (4) the evaluation of waste thickness disposed at a landfill site [20, 23, 51].

In this research 8 electrical resistivity profiles were performed in two different stations (Fig.1b). 4 profiles in January 2020, corresponding to the hot and rainy period. In May 2021, 4 more profiles were executed overlapping those of the first campaign on the western edge of the dump. For the data acquisition resistor ABEM SAS 4000 was used, including 4 rollers of $100 \mathrm{~m}$ cables with 21 outlets that connect to the same number of electrodes. The layout produced by this sequence of cables (100 m and 21 outputs) corresponds to the standard of the reading program hosted by the resistivimeter LUND Imaging System. For data acquisition it was employed a $50 \mathrm{~Hz}$ current frequency, using a multigradient protocol (GRAD4LX8 and GRAD4SX8); the GRAD4LX8 was selected because it provides dense coverage on the nearby surface and adopts the Wenner-Schlumberger protocol $[52,53]$. The electrode spacing for data acquisition was $5 \mathrm{~m}$. All the electrodes take-outs were connected in the GRAD4S8 protocol. The resistivimeter automatically switches the electrodes to serve as current or potential pairs. After the readings, the data was transferred to the resistivimeter, which then takes the readings, 3 minimum and 6 maximums, to obtain the smallest error average between readings. The inversion of the electrical resistivity data obtained in the 10 lines was done based on the standards defined in the software RES2DINV3.59.106, namely: application of the smoothness constraint method in the resistivity values of the final model, calculation of the Jacobian matrix in each iteration, standard Gauss-Newton optimization method [21, $46,50]$. The interpretation of the profiles was based on the direction of each profile and the length of the profiles $(400 \mathrm{~m})$. The analysis zones were delimited, Zone 1 from $0-200 \mathrm{~m}$ (Z1) and Zone 2 from 200-400m (Z2).

\section{Results and discussion}

3.1 Geophysical studies - Electrical resistivity 
The interpretation of the electrical resistivity models allowed the understanding of the leachate formation areas, dynamics, and dispersion of contamination plumes in the groundwater as well as comparing the variations of the resistive anomalies (2020-2021). The following anomalous areas were distinguished: (I) areas of possible leachate formation and enrichment, (II) contamination plumes in subsurface and groundwater.

Profile 1: 2020 (a) and 2021 (b)

The two profiles (a) and (b) extend in the S-N direction and are parallel to the western boundary of the dump (fig.2).

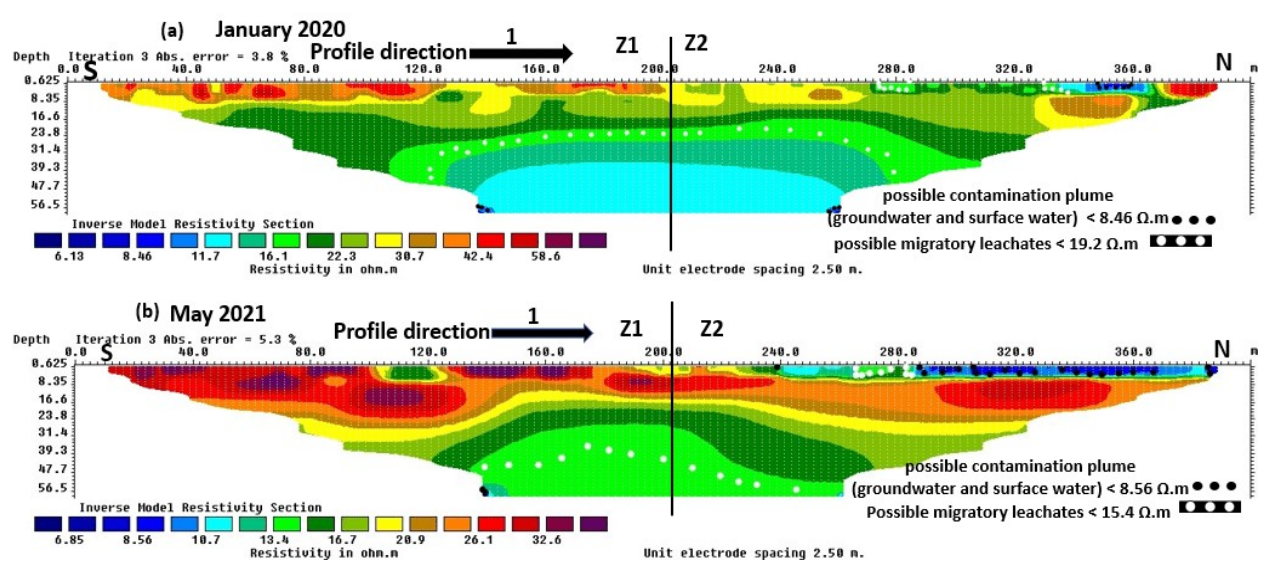

Figure 2. Electrical resistivity model of profile 1, 2020, (a) and 2021 (b).

Zone 1 - From the beginning of the two profiles to the $200 \mathrm{~m}$ surface no significant changes are noted, and in general the resistivity is higher, associated with the rubble and debris of old houses that were erected in this space until the year 2018 [54]. At depth slight differences in resistive layers are noted which may be associated with the effect of variation in rainfall and moisture, abundant in (a) and less (b). The zone of resistivity $<19.2$ $\Omega . \mathrm{m}$ in (a) and < $15.4 \Omega$.m (b) we identify as leachate concentration zone resulting from the vertical migration of leachate from the surface washing of the dump by precipitation that are channeled in the unprotected ditch and parallel to these profiles (Fig. 3b). Wu et al. [55] and Ololade et al. [56] showed that leachate flow in non-isolated areas can cause migration to great depths and groundwater contamination. The leachate accumulation zone $<19.2 \Omega . m(a)$ and $<15.4 \Omega$.m (b) were shown to have variable thicknesses, which may be associated with the effect of the relatively saturated lower layers $<16.1$ to $11.7 \Omega . m$ (a) being more extensive in summer, which causes slow vertical migration at depth and the production of thick plumes at great depth $<8.46 \Omega . \mathrm{m}$ in profile (a) and $<8.56 \Omega . \mathrm{m}$ in profile (b). The leachate migration layers we consider as contaminated $<16.1-11.7 \Omega . m$ (a) and < 13.2 - $10.7 \Omega . m$ (b). At great depth at the southern end of both profiles there is a localised anomalous zone that we interpret as being influenced by groundwater contamination by plumes resulting from vertical leachate migration. In the superficial Zone 2 in both profiles, anomalous zones are evident at $280 \mathrm{~m}$, which are more extensive in profile (b), representing residues humidified by surface water (leachate producer) < $15.4 \Omega . \mathrm{m}$, which are more visible in the north of both profiles and more extensive in profile (b). The very visible plumes in both profiles in surface water the contamination in the natural receiving basin by surface leachates and plumes mobilizing at depth in E-W direction, described in profile 2 . 

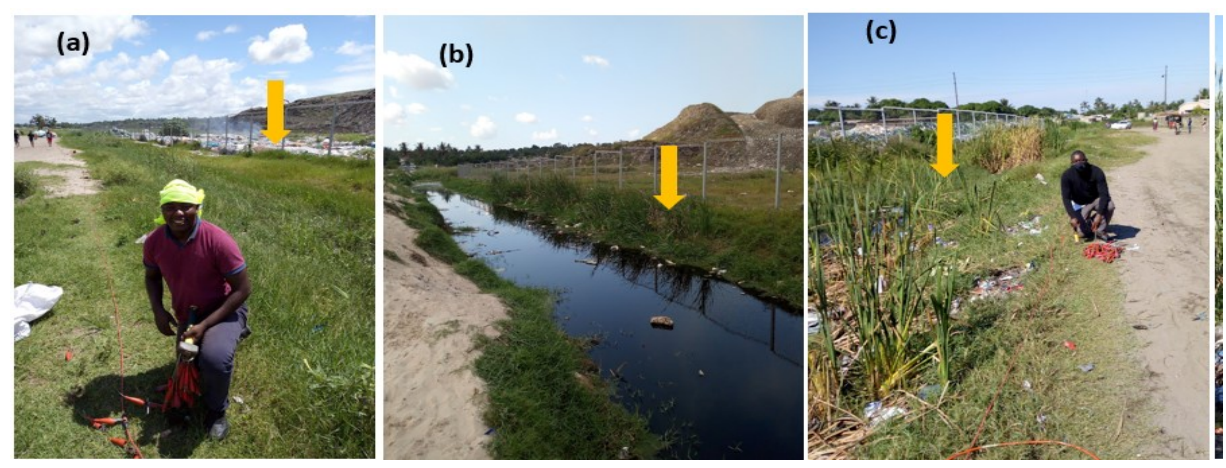

Figure 3. Geophysical surveys: (a) profile 1 in 2020 - The arrow indicates the surface leachate concentration ditch parallel to the profile 1, (b) Drainage ditch with uninsulated surface leachate 2021, (c) profile 1 in 2021.

Profile 22020 (a) and 2021(b)

Profile 2, with a west - east orientation, northern boundary of the dump (Fig.4).

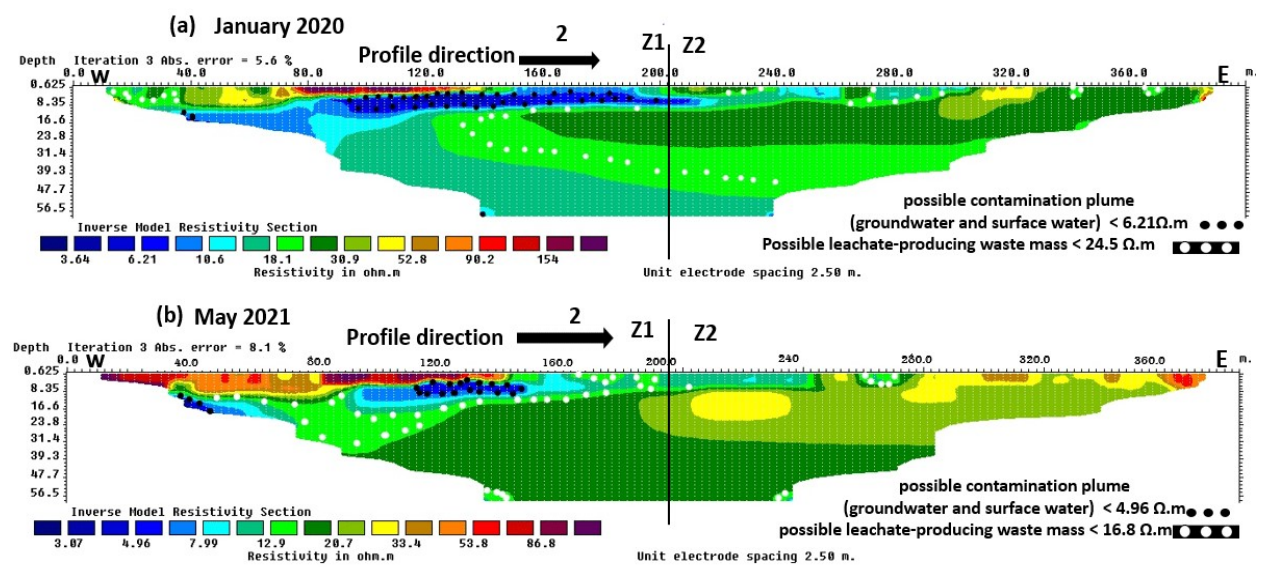

Figure 4. Electrical resistivity model of profile 2, 2020 (a) and 2021 (b).

Zone 1 - from 0 to $80 \mathrm{~m}$ surface, in profile (a) we can notice a marked variation of resistivities. The zones of low resistivity $(<24.5 \Omega . \mathrm{m})$ we interpret as very wet and leached waste production zone, given the new solid waste depositions recorded at this point to the west of the basin. The same profile section (b) showed high resistivities, given the scarcity of precipitation and low ambient temperature. The high temperatures, humidity and age of the dump are primary factors in decomposition and leachate production $[36,47,56]$. From $8.35 \mathrm{~m}$ depth in profile (a) we note an extensive saturated zone that extends in the northern direction and connects to an extensive subsurface flow system. In turn, in profile (b), this saturated zone appears more confined and with an expressive concentration of anomalous values $<4.96 \Omega . \mathrm{m}(\mathrm{b})$ that we interpret as a plume that migrates horizontally in summer in the east-west direction and is confined at this point. Cendón et al. [18] described the aquifer system of this region as semi-confined and that seasonally binds continuously, a fact that is visualized in these bands of the two profiles and that are associated with the transfer of possible plumes at depth. From 80 to $200 \mathrm{~m}$ superficial in profile (a) we verify the alternation of high and low resistivities. The high resistivities we interpret as compact material on the surface, which alternates between debris, rubble, old house debris. From 160 to $200 \mathrm{~m} \mathrm{(a),} \mathrm{we} \mathrm{observe} \mathrm{surface} \mathrm{waters}$ of the natural leachate reception basin, which are constantly enriched by the surface leachates. In this section at a depth of 8.35 to $47.7 \mathrm{~m}$ (a) there is an extensive plume of 
contamination arising from the large mass of wet waste and producing leachates $<24.5$

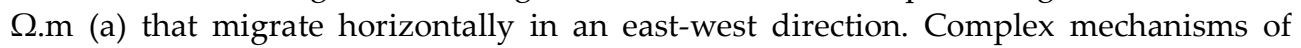
leachate movement from the surface and at depth are also observed. The vertical and horizontal movement of the leachate produces an extensive plume that migrates from $\mathrm{E}-\mathrm{W}<6.21 \Omega . \mathrm{m}$ (a). In profile (b), from 80 to $140 \mathrm{~m}$ the resistivity is higher and with a larger area than in (a) given the significant reduction in the extent of surface water responsible for the decomposition of the waste mass and consequent decrease in resistivity. At the depth of the same section, confined groundwater receives leachate, which moves horizontally from $\mathrm{E}-\mathrm{W}<16.8 \Omega \mathrm{m}(\mathrm{b})$ and a vertical migration between 142.5 to $147.5 \mathrm{~m}$. The contamination plume $<7.9 \Omega . \mathrm{m}(\mathrm{b})$, at this point is quite pronounced and may indicate a high level of contamination, given the reduced dilution and migration environment.

Zone 2 - in (a) between $200 \mathrm{~m}$ to $315 \mathrm{~m}$, shows alternating resistivities between the less moist waste mass $<20.7 \Omega$.m to saturated zones $<10.6 \Omega$.m (b) which represent pits and small surface depressions enriched by surface water and the same characteristics are noted in (b), but with lower moisture extent. From 320 m onwards, in profile (a) an increase in resistivity $>30.8 \Omega$.m is noted which corresponds to waste mass mixed with less moist soils and resistivity $>52.8 \Omega$.m represents compacted dry waste. In profile (b) to the same extent, the increase in resistivity is much more noticeable, which indicates dry waste and soil <33.4 $\Omega . \mathrm{m}$ and compacted waste $>33.4 \Omega$.m. At depth, in both profiles the large mass of waste $<30.94 \Omega . \mathrm{m}(\mathrm{a})$ and $<20.74 \Omega$. m (b) that gains successively moisture in (a) and establishes an extensive area of leachate production $<24.5 \Omega$.m (a) and very confined in $(b)<16.8 \Omega$.m. These differences are the result of the variation in precipitation and temperature in the two seasons studied, which are responsible for the variation in waste mass decomposition, production, and migration of leachate [58].

Profile 32020 (a) and 2021 (b)

Profile 3, with an S-N orientation northwest of the Dump (fig.5).
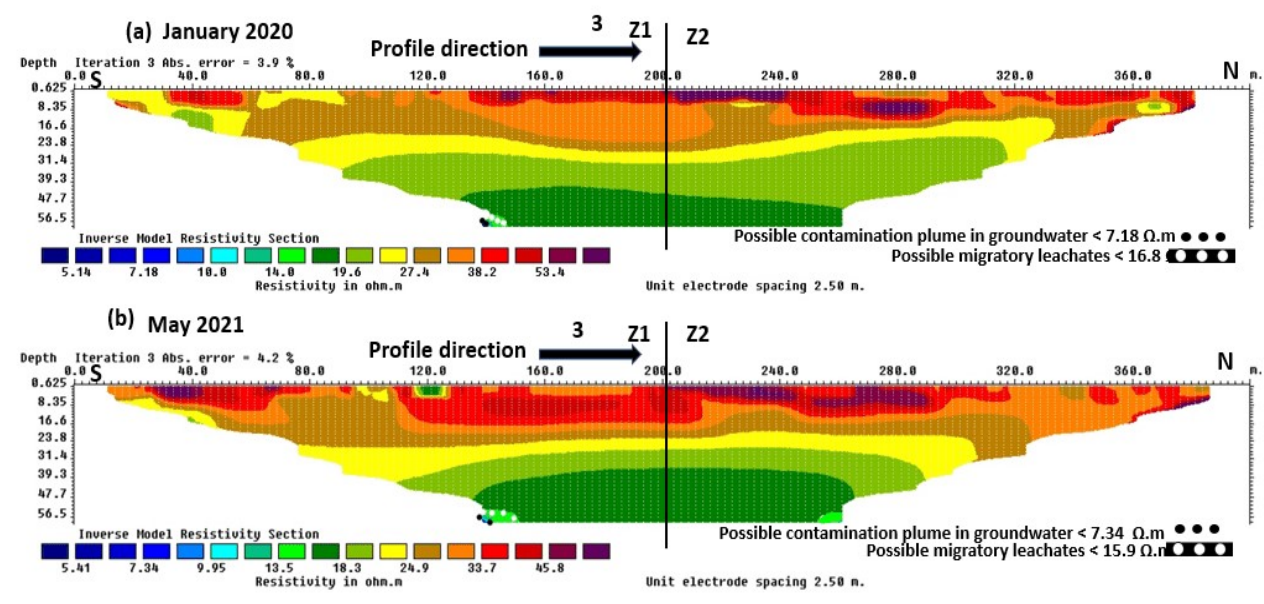

Figure 5. Electrical resistivity model of profile 3, 2020 (a) and 2021 (b).

The execution area of this profile corresponds to the strip that temporarily floods with run-off water from the dump. It was executed to understand the spatial dynamics of possible contamination plumes in the northern direction of the surroundings of the dump (reception basin). At $40 \mathrm{~m}$ in both profiles the influence of moisture in a localized band at depth is noted, evidenced by resistivity $<23.5 \Omega . \mathrm{m}$ in profile (a) and $21.6 \Omega . \mathrm{m}$ (b). In the first profile, the strip occupies a relatively larger area due to the abundant precipitation in this period that infiltrates to the deeper layers. At $140 \mathrm{~m}$ depth there is an anomalous zone in both profiles, which we interpret as a plume of contamination $<7.18$ (a) and $<7.34 \Omega . \mathrm{m}$. We consider that this anomaly corresponds to the northern limit of the 
large plume described in profile 2. From $160 \mathrm{~m}$, in both profiles at all depths, the resistivity tends to be equal, and we consider as typical of local strata and anomalous zones positively > 38.2 $\Omega . \mathrm{m}$ (a) and $>33.7$ correspond to compacted soils or rubble, given the strong movement of cars at these points. The similarity of the data in the two profiles and the absence of low depth anomalous zones show the decreasing effect of the contamination plumes on the subsoil and the subsurface environment as one move away from the dump to the North, due to the natural process of attenuation by dilution and dispersion of the plumes in the natural receiving basin. Similar situations have been described in areas around several dumpsites in Africa, Morocco by El Mouine et al. [59] and Touzani et al. [47], Nigeria by Fatoba et al. [60] and Burkina Faso by Barry et al. [61].

Profile 42020 (a) and 2021 (b)

Profile 4 has SW- NE orientation (a) and the NE-SW (b) profile both overlap (Fig. 6).

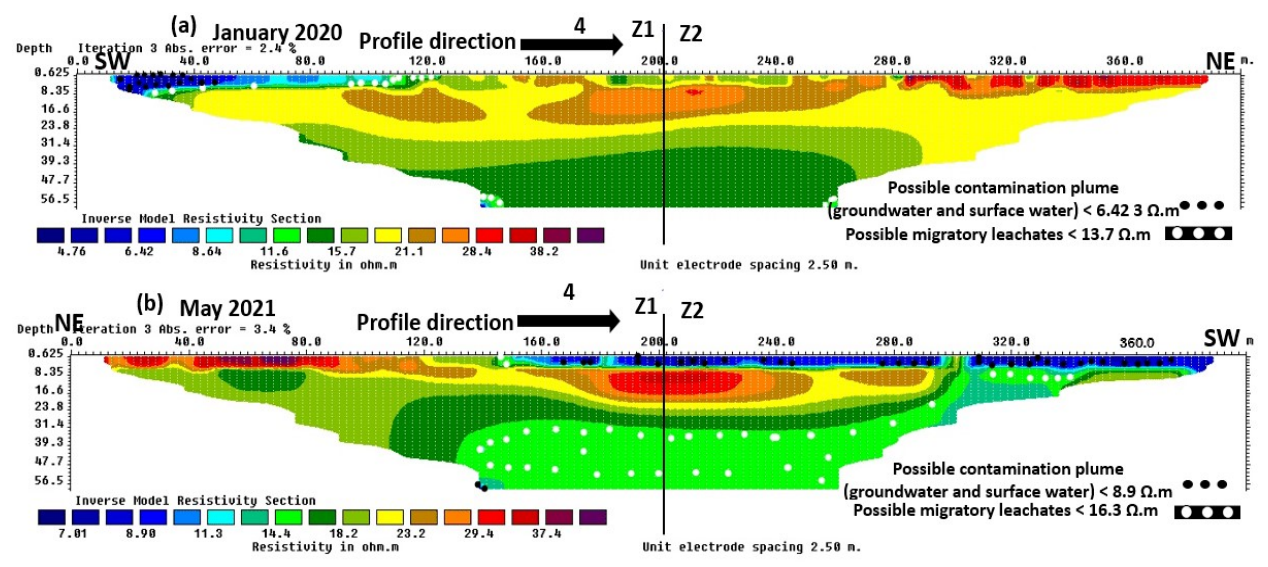

Figure 6. Electrical resistivity model of profile 4, 2020 (a) and 2021 (b).

Zone 1 - Profile 4 (a) from the beginning to $120 \mathrm{~m}$ shallow shows zones with anomalous resistivities. The resistivity $<13.7 \Omega$.m was interpreted as a zone of leachate production and dispersion, resulting from new waste deposits in the southwest of the natural basin. These leachates migrate horizontally in the NE- SW direction and vertically until they mix with groundwater. In profile 4 (b), these anomalies occupy a large area in the dry period and extend over an area of about $240 \mathrm{~m}$ surface as well as at depth $<16.3$ $\Omega . m$. The extensive anomalous area at depth in profile $4(\mathrm{~b})(<16.3 \Omega . \mathrm{m})$ may be associated with a vertical and continuous migration of leachate accumulated at the end of the rainy season in the southeast of natural reception basin.

Zone 2 - In profile 4 (a) from 200 to $400 \mathrm{~m}$ the surface resistivities are generally higher and we interpret them as plastic waste, rubble, and debris from old, buried houses. The same occurs in profile $4 \mathrm{~b}$, from $140 \mathrm{~m}$ to the end of the profile. The resistivity corresponding to possible contamination plumes were interpreted as $<6.42 \Omega . \mathrm{m}$ in (a), < $8.9 \Omega . m$ in (b), which at great depth did not show great changes in the two seasons of the years studied. This reality can be associated with the local aquifer system, which is described as semi-confined in clay layers [18].

\subsection{Spatial distribution of possible leachate plumes (2020-2021)}

The spatial distribution of the plumes in the study period (2020-2021) (fig.8), shows predominantly an east-west movement of the deep contamination plumes and surface leachates in profiles 1 and 2, that mix with the surface waters of the natural basin to the west and migrate vertically to the groundwater causing resistive anomalies at a larger scale in winter (1). The same flow direction was described by Bernardo et al. [20]. The flow is conditioned by the arrangement of the local topography (soft dune E-W), which collects all 
the leachate from the subsurface compression of the waste, since it is at a higher altitude than the local relief. Another relevant factor in this direction of contaminant flow is the recent construction of leachate drainage channels that create natural leachate flows in the E-W direction (fig. 4.b). However, the dilution process of leachate plumes shows a varied dispersion direction in the natural reception basin and groundwater (fig. $7 .<4.26-<8.5$ $\Omega . m)$, suggesting that contamination migrates in several directions. Similar anomalous values were interpreted as plumes in groundwater by Harjito et al. [62] 3-9 $\Omega . m$ near a Bantul waste dump in Indonesia, Bichet et al. [28] refer between $5-12 \Omega . m$ at a landfill in Belfort (France) and Ugbor et al. [25] 3.12 - $8.7 \Omega . m$ in the surrounding of the Onitsha waste dump in southeast Nigeria. To the southwest of the natural basin reception there is a subplume of contamination resulting from new depositions producing leachate that migrates to the southwest during the wet season and in all directions during the dry season (profile 4 ). The spatialization of the plumes shows that as one moves away from the dump the anomalies tend to disappear (profile 3), suggesting the attenuation of the contamination by the local lithology. The role of lithology and groundwater in the attenuation of contamination by leachate plumes in the surrounding of waste dumps has been described in many studies for example by Fatoba et al. [60] and Biosca et al. [63].

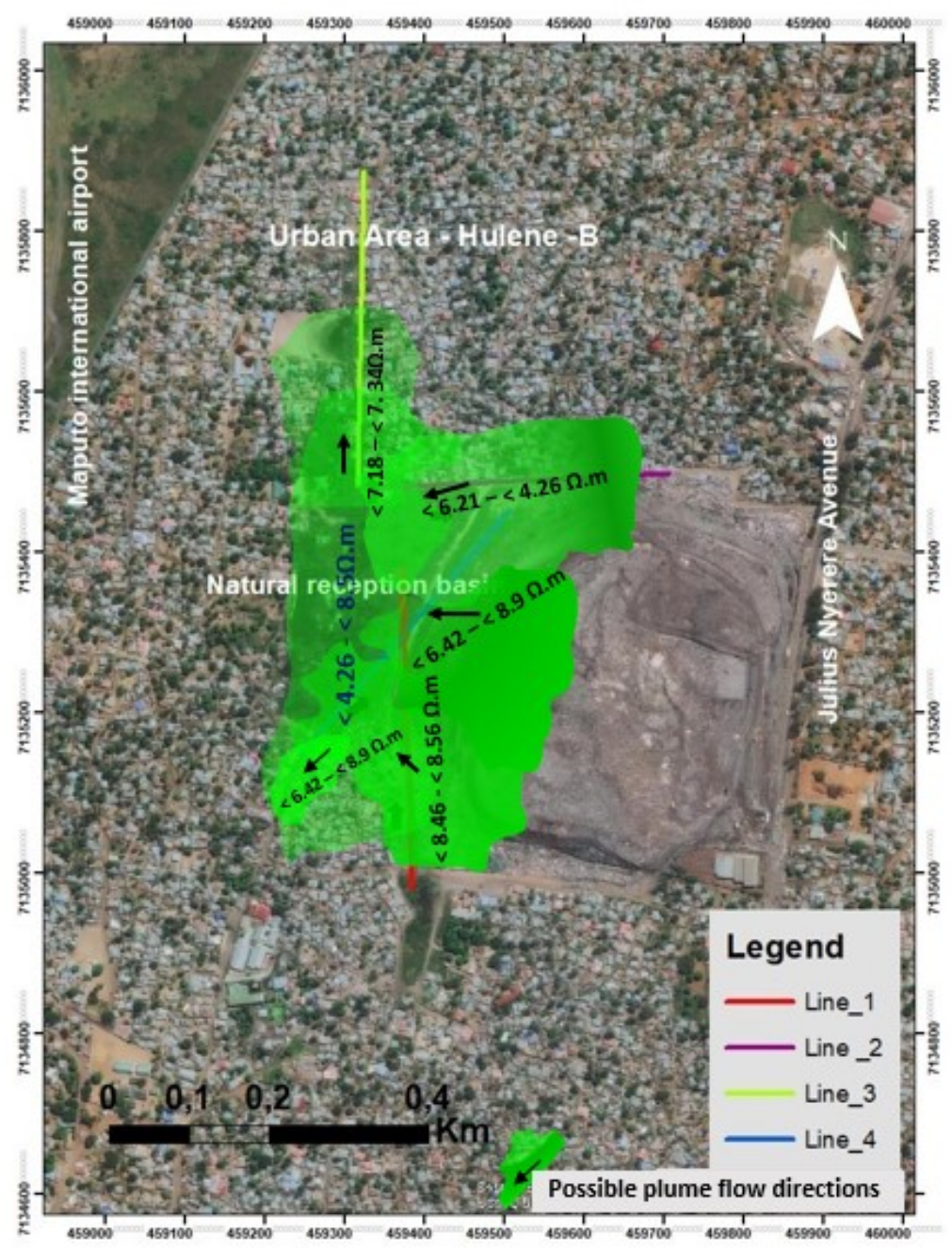

Figure 7. Possible flow directions of contamination plumes 2020-2021, modified from Bernardo et al. [20]

\section{Conclusions}


The application of the electrical resistivity method to the study of the dynamics of contamination plumes around the Hulene - B waste dump has proved to be efficient in identifying anomalous areas of low resistivity that we consider as leachate production and contamination plume migration zones in lithological substrates and surface and groundwater.

The contamination plumes in the two seasons show predominantly an E-W movement (profiles 1 and 2) and vertical and horizontal migration. In profile 3, the S-N movement influenced by the diffusion of the large plume described in profile 2 was evidenced by the anomalies at the southern end of the profile (3) in the two studied periods 2020-2021. In profile 4 the plumes assume a NE-SW movement and their enrichment is associated with the new deposition at the southwestern limit of the natural basin. The four overlapping profiles show that the leachate enrichment zones play a relevant role in the enrichment, flow, and diffusion of the plumes into groundwater and surface water.

The spatialized electrical resistivity models at the studied stations show that the anomalies in the subsurface environment decrease as one moves away from the dump to the north (profile 3), which reveals the attenuating effect of groundwater and lithological substrates. Thus, the resistivity models have proven to be efficient in assisting in the adoption of structural measures for monitoring the possible leachate contamination flows in the lithologies, surface and groundwater around the Hulene - B waste dump, Maputo, Mozambique.

Studies are ongoing to quantify the chemical contamination of groundwater and surface water.

Author Contributions: Conceptualization, B.B. and F.R.; methodology, B.B.; software, B.B.; validation, B.B., C.C. and F.R.; formal analysis, F.R.; investigation, B.B.; resources, B.B.; data curation, B.B.; writing - original draft preparation, B.B.; writing-review and editing, B.B. and F.R.; visualization, B.B.; supervision, F.R. and C.C.; project administration, F.R.; funding acquisition, B.B. All authors have read and agreed to the published version of the manuscript.

\section{Acknowledgments:}

This work was partially supported by GeoBioTec (UIDB/04035/2020) Research Center, funded by FEDER funds through the Operational Program Competitiveness Factors COMPETE and by National funds through FCT. First author acknowledges grants from the Portuguese Institute Camões and FNI (Investigation National Fund Mozambique).

Conflicts of Interest: The authors declare no conflict of interest

\section{References}

1. Brahmi, S.; Baali, F.; Hadji, Brhahmi, S.; Hamad, A.; Rahal, O.; Zerrouki, H.; Saadali, B.; Hamed,Y. Assessment of groundwater and soil pollution by leachate using electrical resistivity and induced polarization imaging survey, case of Tebessa municipal landfill, NE Algeria, Arab. J. Geosci. 2021., vol. 14, no. 4, https://doi.org/10.1007/s12517-021-06571-z

2. Ooi, J. K; Woon, K. S. Simultaneous greenhouse gas reduction and cost optimisation of municipal solid waste management system in Malaysia,.Chem. Eng. Trans. 2021, vol. 83, pp. 487-492, DOI: $10.3303 / C E T 2183082$

3. Ferronato, N; Torretta, V. Waste management in developing countries: A review of global issues,.Int. J. Environ.Res. Public Health. 2019, vol. 16, no. 6. https:// doi:10.3390/ijerph16061060

4. Nanda, S.; Berruti, F. Municipal solid waste management and landfilling technologies: a review," Environ. Chem. Lett., 2021. vol. 19, no. 2,1433-1456. https://doi.org/10.1007/s10311-020-01100-y

5. Marino, A.; Pariso, P. Comparing European countries' performances in the transition towards the Circular Economy, Sci. Total Environ. 2020, vol. 729, 138-142. https://doi.org/10.1016/j.scitotenv.2020.138142

6. Koliyabandara, S. M. P.; Asitha, A.T. C.; Sudantha, L.; C. Siriwardana, Assessment of the impact of an open dumpsite on the surface water quality deterioration in Karadiyana, Sri Lanka, Environ. Nanotechnology, Monit. Manag. 2019,, vol. 14, $100-371$. https://doi.org/10.1016/j.enmm.2020.100371. 
7. Morita, A. K.M.; Ibelli-Bianco, C.; Anache , J. A.A.; Coutinho, J. V.; Pelinson, N. S.; Nobrega, J.;Rosalem, L.M.P.; Leite, C. M.C.; Niviadonski, L. M.;Manastella, C.; Wendland, E. Pollution threat to water and soil quality by dumpsites and non-sanitary landfills in Brazil: A review, Waste Manag. 2021, vol. 131, 163-176. https://doi.org/10.1016/j.wasman.2021.06.004.

8. Wijekoon, P. ; Koliyabandara, P. A.; Cooray, A. T. ; Lam, S. S.; Athapattu, B. C. L.; Vithanage, M. Progress and prospects in mitigation of landfill leachate pollution: Risk, pollution potential, treatment and challenges, J. Hazard. Mater. 2022., vol. 421, 2021, 126627. https://doi.org/10.1016/j.jhazmat.2021.126627.

9. Jayawardhana, Y.; Kumarathilaka, P.; Herath, I.; Vithanage, M.Municipal Solid Waste Biochar for Prevention of Pollution From Landfill Leachate. 2016. Elsevier Inc. https://doi.org/10.1016/B978-0-12-803837-6.00006-8.

10. Wang, F.; Song, K.; He, X.; Peng, Y.; Liu, D.; Liu, J. Identification of groundwater pollution characteristics and health risk assessment of a landfill in a low permeability area, Int. J. Environ. Res. Public Health, 2021.vol. 18, no. 14. https://doi.org/10.3390/ijerph18147690.

11. Kumar, G.; Reddy, K. R.; McDougall, J. Numerical modeling of coupled biochemical and thermal behavior of municipal solid waste in landfills, Comput. Geotech., 2020. vol. 128, 1-70. https://doi.org/10.1016/j.compgeo.2020.103836.

12. Khattak, S. A.; Rashid, A.; Tariq, M.; Ali, A.; Gao, X.; Ayub, M.; Javed, A. Potential risk and source distribution of groundwater contamination by mercury in district Swabi, Pakistan: Application of multivariate study, Environ. Dev. Sustain. 2021., vol. 23, no. 2, 2279-2297. https://doi.org/10.1007/s10668-020-00674-5.

13. Iddrisu T. I.; Debrah, K. D. Consequences of Poor Landfill Management on the People of Gbalahi in the Sagnarigu Municipality of Northern Ghana, J. Geosci. Environ. Prot. 2021, vol. 09, no. 08, 211-224. https://doi.org/10.4236/gep.2021.98014

14. Tvedten, I.; Candiracci, S. Flooding our eyes with rubbish: urban waste management in Maputo, Mozambique, Environ. Urban. 2018, vol. 30, no. 2, pp. 631-646, Environment Protection, 9, 211-224.

15. Sarmento, L.; Tokai, A.; Hanashima, A. Analyzing the structure of barriers to municipal solid waste management policy planning in Maputo city , Mozambique, Environ. Dev. 2015, vol. 16, 76-89, http://dx.doi.org/10.1016/j.envdev.2015.07.002]

16. Buque, L. I. B.; Ribeiro, H. Panorama da coleta seletiva com catadores no município de Maputo, Moçambique: Desafios e perspectivas, Saude e Soc. 2015., vol. 24, no. 1, 298-307. In Portuguese.

17. Serra, C. Da problemática ambiental à mudança: rumo à um mundo melhor, Maputo, 2012, Editora Escolar.

18. Cendón D. I.; Haldorsen, S.; Chen, J.; Hankin,S.; Nogueira, G.E.H.; Momade, F.; Achimo, M.; Muiuane,E.; Mugabe, J.; Stigter, Ti. Hydrogeochemical aquifer characterization and its implication for groundwater development in the Maputo district, Mozambique, Quat. Int.2019., vol. 547, pp. 113-126, 2020. https://doi.org/10.1016/j.quaint.2019.06.024

19. Vicente, E. M.; Jermy, C. A.; Schreiner, H. D. Urban geology of Maputo, Mocambique, Geol. Soc. London, 2006.no. 338,1-13

20. Bernardo, B.; Candeias, C.; Rocha, F. Application of Geophysics in geo-environmental diagnosis on the surroundings of the Hulene-B waste dump, Maputo, Mozambique, J. African Earth Sci. 2022, vol. 185, 104415. https://doi.org/10.1016/j.jafrearsci.2021.104415.

21. Adamo, N; Al-Ansari, N.V.; Laue,S.; Knutsson, S. Geophysical Methods and their Applications in Dam Safety Monitoring, J. Earth Sci. Geotech. Eng. 2020, vol. 11, no. 1, pp. 291-345. https://doi.org/10.47260/jesge/1118.

22. Dhakate, R.; Mogali, N. J.; Modi, D. Characterization of proposed waste disposal site of granite quarry pits near Hyderabad using hydro-geophysical and groundwater modeling studies, Environ. Earth Sci. 2021, vol. 80, no. 16, 1-20. https://doi.org/10.1007/s12665-021-09821-1.

23. Helene L. P. I.; Moreira, C. A. Analysis of Leachate Generation Dynamics in a Closed Municipal Solid Waste Landfill by Means of Geophysical Data (DC Resistivity and Self-Potential Methods)," Pure Appl. Geophys. 2021, vol. 178, no. 4, $1355-1367$. https://doi.org/10.1007/s00024-021-02700-7.

24. Arifin M.H.; Kayode, J.S.; Ismail, M.K.I; Abdullah, A.M.; Embrandiri, A.; Nazer, N. S.M.; Azmi, A. Environmental hazard assessment of industrial and municipal waste materials with the applications of RES2-D method and 3-D Oasis Montaj modeling: A case study at Kepong, Kuala Lumpur, Peninsula Malaysia, J. Hazard. Mater. 2021, vol. 406, May 2020, 124282. https://doi.org/10.1016/j.jhazmat.2020.124282.

25. Ugbor, C. C.; kwuagwu, I. E.I; Ogboke, O. J. 2D inversion of electrical resistivity investigation of contaminant plume around a dumpsite near Onitsha expressway in southeastern Nigeria, Sci. Rep. 2021, vol. 11, no. 1, 1-14. https://doi.org/10.1038/s41598-021-91019-3.

26. Kayode, J. S.; Arifin, M. H.; Nawawi, M. Characterization of a Proposed Quarry Site using Multi-Electrode Electrical Resistivity Tomography, Sains Malaysiana, 2019, vol. 48, no. 5, pp. 945-963. http://dx.doi.org/10.17576/jsm-2019-4805-03

27. Lau, A. M. P.; Ferreira, F. J. F.; Stevanato, R.; da Rosa Filho, E. F. Geophysical and physicochemical investigations of an area contaminated by tannery waste: a case study from southern Brazil," Environ. Earth Sci. 2019, vol. 78, no. 16, 1-16. https://doi.org/10.1007/s12665-019-8536-1.

28. Bichet, V.; Grisey, E.; Aleya, L. Spatial characterization of leachate plume using electrical resistivity tomography in a landfill composed of old and new cells (Belfort, France), Eng.2016, Geol., vol. 211, 61-73. http://dx.doi.org/10.1016/j.enggeo.2016.06.026

29. Bernstone, C.; Dahlin, T.; Ohlsson, T.; Hogland, W. DC-resistivity mapping of internal landfill structures: Two pre-excavation surveys, Environ. Geol.2000, vol. 39, no. 3-4, 360-371.

30. Qiu, L.; Yang, Y.; Ma, L.; Qiao, J. Research on the electrical resistivity characteristics of statue remolded soil, IOP Conf. Ser. Earth Environ. 2021, Sci., vol. 692, no. 4. https://doi:10.1088/1755-1315/692/4/04207.

31. Nassereddine, M.; Rizk, J.; Nasserddine, G. Soil Resistivity Structure and Its Implication on the Pole Grid Resistance for Transmission Lines, 2013, vol. 7, no. 1, 19-23, scholar. waset.org/1307-6892/6614. 
32. Scarlet, M.; Bandeira, S. Pollution in Maputo Bay. In: Bandeira, S., Paula, J. (Eds.), The Maputo Bay Ecosystem. WIOMSA, Zanzibar Town, 2014, 427.

33. JICA STUDY TEAM, Final report road development of the city of maputo jica study team, 2014, no. 1

34. Palalane, j.; Segala, I.; Opressa, I. Urbanização e desenvolvimento municipal em Moçambique: gestão de resíduos sólidos. Instituto Brasileiro de Administração Municipal, Área de desenvolvimento Urbano e Meio Ambiente, RJ, $2008,12$.

35. Ferrão. D.A.G. Evaluation of removal and disposal of solid waste in Maputo City, Mozambique, Master's thesis, University of Cape Town, Cape Town, South Africa, 2006, http://hdl.handle.net/11427/4851.

36. Wang, X. X.; bang, Y.; Chang, J.; Deng, Z.; Chen, S, J. 3D spatial distribution of old landfills and groundwater pollution from electrical resistivity tomography with fuzzy set theory, Explor. Geophys.,2021. https://doi.org/10.1080/08123985.2021.1917292

37. Sallwey, J.; Hettiarachchi, H.; Hülsmann, S. Challenges and opportunities in municipal solid waste management in mozambique: A review in the light of nexus thinking, AIMS Environ. Sci., 2017, vol. 4, no. 5, 621-639, DOI: 10.3934/environsci.2017.5.621.

38. Nogueira, G.; Stigter, T. Y. ; Zhou, Y.; Mussa, F.; Juizo, D. Understanding groundwater salinization mechanisms to secure freshwater resources in the water-scarce city of Maputo, Mozambique, Sci. Total Environ. 2019, vol. 661, $723-736$. https://doi.org/10.1016/j.scitotenv.2018.12.343.

39. Muchimbane. B. D. Study of groundwater contamination indicators for sanitation systems in situ - Urban Distric 4, Maputo City, Mozambique, 2010. https://doi 10.11606/D.44.2010.tde-06052010-153107. In Portuguese.

40. Afonso, R. M. The geology of Mozambique - news about the geological map of Mozambique, 1:2000000, Maputo, 1978. In Portuguese.

41. Momade, F. Momade, F.J., Ferrara, M., Oliveira, J.T. Notícia explicativa da carta geológica 2532 Maputo (Escala 1:50 000), 1996, Maputo. In Portuguese.

42. INAM [Mozambique National Meteorological Institute]. Synthesis of temperature and precipitation data 1987-2019, adapted by the author based on data provided by the Maputo meteorological station.

43. CIAT; World Bank. Climate-Smart Agriculture in Mozambique, Clim. Agric. Mozambique, 2017.1-25.

44. Dos Muchangos, A. Paisagens e Regiões Naturais, Maputo, Editora Escolar, 1999, pp. 5-163.

45. Mama, C. N.; Nnaji, C. C.; Nnam, J. P.; Opata, O. C. Environmental burden of unprocessed solid waste handling in Enugu State, Nigeria, Environ. Sci. Pollut. Res. 2021, vol. 28, no. 15, 19439-19457. https://doi.org/10.1007/s11356-020-12265-y

46. Udosen, N. I. Geo-electrical modeling of leachate contamination at a major waste disposal site in south-eastern Nigeria, Model. Earth Syst. Environ. 2021, no. 0123456789. https://doi.org/10.1007/s40808-021-01120-9

47. Touzani, M.; Mohsine, I.; Ouardi, J.; Kacimi, I.; Morarech, M.; El Bahajji, M.H.; Bouramtane, T.; Tiouiouine, A.; Yameogo, S.; El Mahrad, B. Mapping the Pollution Plume Using the Self-Potential Geophysical Method: Case of Oum Azza Landfill, Rabat, Morocco. Water 2021, 13, 961. https://doi.org/10.3390/w13070961.

48. Frid, V.; Liskevitch, G. Application of geophysical methods as an integral part of geotechnical site characterization. Environ. Geol., 53, 1503- 1508, 2018, https://doi.org/10.1007/s00254-007-0761-3.

49. Koda, E.; Tkaczyk, A.; Lech, M.; Osiński, P. Application of Electrical Resistivity Data Sets for the Evaluation of the Pollution Concentration Level within Landfill Subsoil. Appl. Sci. 2017, 7, 262. https://doi.org/10.3390/app7030262.

50. Geotomo. RES2DINV ver. 3.59 - Rapid 2-D Resistivity \& IP inversion using the least-squares method Wenner $(\alpha, \beta, \gamma)$, dipole-dipole, inline pole-pole, pole- dipole, equatorial dipole-dipole, offset pole-dipole, Wenner-Schlumberger, gradient and non-conventional arrays, 2010, 1-148.

51. Nta, S. A.M. J.; Ayotamuno, A. H.; Okparanma, R. N.; Leachate Characterization from Municipal Solid Waste Dump Site and Its Adverse Impacts on Surface Water Quality Downstream - Uyo Village Road, Akwa Ibom State - Nigeria," J. Eng. Res. Reports, 2020, vol. 13, no. 2, 11-19. https://doi: 10.9734/JERR/2020/v13i217096.

52. Ejiogu, B. C.; Opara, A. I.; Nwosu, E. I Nwofor, O. K.; Onyema, J. C.; Chinaka, J. C. Estimates of aquifer geo-hydraulic and vulnerability characteristics of Imo State and environs, Southeastern Nigeria, using electrical conductivity data, Environ. Monit. Assess., 2019, vol. 191, no. 4, 1-19. https://doi.org/10.1007/s10661-019-7335-1.

53. Vasantrao, B. M.; Bhaskarrao, P. J.; Mukund, B. A.; Baburao, G. R.; Narayan, P. S. Comparative study of Wenner and Schlumberger electrical resistivity method for groundwater investigation: a case study from Dhule district (M.S.), India, Appl. Water Sci. 2017, vol. 7, no. 8, 4321-4340. https://doi.org/10.1007/s13201-017-0576-7.

54. VOA. Desabamento de lixeira deixa 17 mortos em Maputo. Voice of America News, 2018, Available online: https://www.voaportugues.com/a/desabamento-lixeira-17-mortos-maputo/4260624.html Accessed on 30-09-2021.

55. Wu, Q.; Hu, W.; Wang, H.; Liu, P.; Wang, X.; Huang, B. Spatial distribution, ecological risk and sources of heavy metals in soils from a typical economic development area, Southeastern China, Sci. Total Environ., vol. 2021, 780, 146557. https://doi.org/10.1016/j.enggeo.2021.106259.

56. Ololade, O. O.; Mavimbela, S.; S. A. Oke, Makhadi, R. Impact of leachate from northern landfill site in Bloemfontein on water and soil quality: Implications for water and food security, Sustain. 2019, vol. 11, no. 15. https:// doi:10.3390/su11154238

57. Chaudhary, R.; Nain, P.; Kumar, A. Temporal variation of leachate pollution index of Indian landfill sites and associated human health risk, Environ. Sci. Pollut. Res. 2021, vol. 28, no. 22, 28391-28406. https://doi.org/10.1007/s11356-021-12383-1

58. Ali, Q. H.S.; Sugihen, R.; Munawar, E.; Adisalamun, E. The Effect of Leachate Resirculation on the Greenhouse Gases Emission from Municipal Solid Waste (MSW) Landfill in Tropical Climate Region, IOP Conf. Ser. Mater. Sci. Eng. 2020, vol. 778, no. 1. https://doi:10.1088/1757-899X/778/1/012138. 
59. El Mouine, H; El Hamdi, A.; Morarech, M.; Kacimi, I.; Touzani, M.; Mohsine, I.; Tiouiouine, A.; Ouardi, J.; Zouahri, A.; Yachou, H.; Dakak, H. Landfill Pollution Plume Survey in the Moroccan Tadla Using Spontaneous Potential. Water 2021, $13,910$. https://doi.org/10.3390/w13070910.

60. Fatoba, J. O.; Eluwole, A. B.; Sanuade, O. A.; Hammed, O. S.; Igboama, W. N.; Amosun, J. O. Geophysical and geochemical assessments of the environmental impact of Abule-Egba landfill, southwestern Nigeria, Model. Earth Syst. Environ. 2021, vol. 7, no. 2, pp. 695-701. https://doi.org/10.1007/s40808-020-00991-8.

61 Barry A.A.; Yameogo, S.; Ayach, M.; Jabrane, M.; Tiouiouine, A.; Nakolendousse, S.; Lazar, H.; Filki, A.; Touzani, M.; Mohsine, I. Mapping Contaminant Plume at a Landfill in a Crystalline Basement Terrain in Ouagadougou, Burkina Faso, Using Self-Potential Geophysical Technique. Water 2021, 13, 1212. https://doi.org/10.3390/w13091212.

62. Harjito, S.; Gunawan, T.; Maskuri, M. Underground leachate distribution based on electrical resistivity tomography in Piyungan landfill, Bantul," Indones. J. Geogr. 2018, vol. 50, no. 1, pp. 34-40. DOI: http://dx.doi.org/ 10.22146/ijg.18315

63. Biosca, B. L.; Arévalo-Lomas, M.; Izquierdo-Díaz, J. D. Detection of chlorinated contaminants coming from the manufacture of lindane in a surface detritic aquifer by electrical resistivity tomography, J. Appl. Geophys. 2021, vol. 191.

https://doi.org/10.1016/j.jappgeo.2021.104358 